\title{
BRAINSTEM AUDITORY EVOKED POTENTIALS FINDINGS IN ANKYLOSING SPONDYLITIS
}

\author{
Iulia Georgiana Stamate, ${ }^{1,2}$, Daniela Marilena Trofin ${ }^{3}$, Elena Rezus ${ }^{1,2}$, \\ Cristian Dinu Popescu1,3 \\ 1 "Gr. T. Popa" University of Medicine and Pharmacy Iasi, Romania \\ ${ }^{2}$ Rheumatology Clinic, Rehabilitation Hospital Iasi, Romania \\ ${ }^{3}$ Neurology Clinic, Rehabilitation Hospital Iasi, Romania
}

\begin{abstract}
Background. Ankylosing spondylitis (AS) is a chronic inflammatory potentially debilitating disease predominantly affecting the axial skeleton. A few intermittently published studies and research have proved the existence of some not yet explained neurophysiologic abnormalities in patients with AS.

Objectives. The aim of this study was to investigate the brainstem auditory evoked potentials and its relation with clinical findings, laboratory tests and pharmacological therapy used in patients with AS.

Material and method. Thirty-nine patients with AS were included in the study. The control group was composed of 50 healthy subjects. BAEP were recorded for all subjects. Patients were assessed by clinical specific tests, inflammatory laboratory tests, Bath Ankylosing Spondylitis Functional Index (BASFI), Bath Ankylosing Spondylitis Disease Activity Index (BASDAI) and type of pharmacological therapy.

Results. The results have shown differences between the control group and the patients with AS in most of the wave latencies. Correlations Schober test, Ott index, chest expansion measurement and BASDAI were significant for some waves. CRP seems to be more valuable than ESR as a possible marker for neurologic subclinical involvement. Axial AS is more likely to be associated with BAEP abnormalities. There were also differences between the group with TNF alpha blockers therapy comparative with the group with other therapies.

Conclusions. This study highlights some abnormalities of BAEP in patients with AS. Diagnosis of multiple sclerosis or demyelination due to administration of TNF alpha blockers should be excluded in medical practice. Collaboration between neurologists and rheumatologists should be considered in monitoring AS patients.
\end{abstract}

Keywords: ankylosing spondylitis, auditory evoked potentials, TNF-alpha blockers, subclinical neurologic involvement

\section{Acknowledgement}

This work received financial support through the "Program of excellence in multidisciplinary doctoral and postdoctoral research in chronic diseases" contract number POSDRU/159/1.5/S/133377, financed by the European Social Fund through "Human Resources Development" Operational Programme 2007-2013.

\section{INTRODUCTION}

Ankylosing spondylitis (AS) is a chronic inflammatory potentially debilitating disease predominantly affecting the axial skeleton. Progression towards irreversible ankylosis due to vertebral fusion causes severe functional disability, with important impact on quality of life. Peripheral joints arthritis and other extra-articular organs such as the skin, eyes, pulmonar, cardiovascular and neurologic system are less frequently involved. The disease affects mostly HLA-B27-positive population, especially the male gender. The onset is usually in the second or third decade of life. (1-3)

Most common neurological complications associated with AS are C1-C2 subluxation, spinal stenosis in the cervical or lumbar regions, cauda equina syndrome and radiculopathy. AS patients in

Author for correspondence:

Iulia Georgiana Stamate, "Gr. T. Popa” University of Medicine and Pharmacy, 16 Universității Str., lasi, Romania

E-mail: igstamate@gmail.com 
latest stages of disease have an increased risk for spinal fractures with minor trauma due to association of osteoporosis and vertebral fusion progression leading to a long bony column. $(1,4,5)$

\section{AIM AND OBJECTIVES}

A few intermittently published studies and research have proved the existence of some not yet explained neurophysiologic abnormalities in patients with AS. Somatosensory evoked potentials, auditory evoked potentials, visual evoked potentials and magnetic motor evoked potentials abnormalities have been reported. (6-9) Furthermore, sporadic associations of AS and multiple sclerosis was also reported. (10-15) Neurologic complications largely due to demyelination mechanisms may be present in AS patients treated with TNF alpha blockers. (16-25)

The aim of this study was to investigate the brainstem auditory evoked potentials (BAEP) and its relation with clinical findings, laboratory tests and pharmacological therapy used in patients with AS.

\section{MATERIAL AND METHOD}

Thirty-nine patients with AS were included in the study. The control group was composed of 50 healthy medication-free adults. All patients have been assessed in Rheumatology Department and BAEP were recorded in Neurology Department, both in Clinical Rehabilitation Hospital Of Iasi, Romania. This study has been approved by the institutional review board. Prior to study inclusion, the informed consent was signed by all subjects from both groups.

BAEP were performed with Nihon Kohden Neuropack for all patients and for all voluntaries in the control group. We used $80 \mathrm{~dB}$ HL alternating polarity clicks in each ear at a rate of $10 / \mathrm{s}$ and a masking white noise of $40 \mathrm{~dB}$ was used for the unstimulated ear. The electrodes were placed as following: ground electrode in the midline frontal area, the reference electrode at vertex and the active electrodes (A1, A2) at the ear lobes. We recorded the latencies of all the waves: I, II, III, IV and $\mathrm{V}$ for and the Interval Latencies (IL): I-III, III$\mathrm{V}$ and I-V. Patients were assessed by clinical specific tests such as Schober test, Ott index, chest expansion measurement, inflammatory laboratory tests: erythrocyte sedimentation rate (ESR), C reactive protein (CRP), indexes: Bath Ankylosing Spondylitis Functional Index (BASFI), Bath Anky- losing Spondylitis Disease Activity Index (BASDAI) and type of pharmacological therapy. The diagnosis of AS was made according to the modified New York criteria. (26)

All these parameters have been processed using the Statistical Package for Social Sciences (SPSS), version 16.0 for Windows. For the correlation test, $\mathrm{p}$ value of $<0.05$ was considered statistically significant.

\section{RESULTS AND DISCUSSIONS}

The mean age of all the 39 patients, 26 males and 13 females, included in this study, was $40.65 \pm 14.34$ years and the mean duration of disease of the patients was $13.31 \pm 7.52$ years.

BASDAI had a mean of $3,4 \pm 2.3$ and BASFI was $4.1 \pm 1,3$. Most of the patients $(n=25)$ were taking Nonsteroidal anti-inflammatory drugs (NSAID) or sulfasalazine (SSZ) or the association between these drugs. Fourteen patients were treated with TNF-alpha blockers. BAEP results for all SA patients included in the study may be seen in Table 1.

TABLE 1. BAEP results for all SA patients included in the study

\begin{tabular}{|l|c|c|c|c|c|c|c|}
\hline $\begin{array}{l}\text { WAVE/ } \\
\text { INTERVAL }\end{array}$ & $\mathbf{n}$ & $\bar{X}$ & $\mathbf{\pm} \mathbf{s}^{\bar{x}}$ & $\mathbf{s}$ & $\mathbf{V} \%$ & Min & Max \\
\hline I $\boldsymbol{L}$ & 39 & 1.62 & 0.062 & 0.389 & 24.088 & 0.77 & 3.23 \\
\hline I $\boldsymbol{R}$ & 39 & 1.64 & 0.067 & 0.421 & 25.627 & 0.91 & 3.28 \\
\hline II $\boldsymbol{L}$ & 39 & 2.72 & 0.095 & 0.59 & 21.7 & 1.67 & 5.31 \\
\hline II $\boldsymbol{R}$ & 39 & 2.77 & 0.131 & 0.816 & 29.489 & 1.87 & 6.99 \\
\hline III $\boldsymbol{L}$ & 39 & 3.79 & 0.096 & 0.598 & 15.781 & 2.65 & 6.25 \\
\hline III $\boldsymbol{R}$ & 39 & 3.69 & 0.077 & 0.483 & 13.097 & 2.72 & 5.43 \\
\hline IV $\boldsymbol{L}$ & 39 & 4.83 & 0.095 & 0.591 & 12.234 & 3.71 & 7.29 \\
\hline IV $\boldsymbol{R}$ & 39 & 4.74 & 0.078 & 0.49 & 10.332 & 3.72 & 6.26 \\
\hline V $\boldsymbol{L}$ & 39 & 5.83 & 0.093 & 0.582 & 9.988 & 5.17 & 8.45 \\
\hline V $\boldsymbol{R}$ & 39 & 5.7 & 0.07 & 0.44 & 7.709 & 4.98 & 7.2 \\
\hline I-III $\boldsymbol{L}$ & 39 & 2.16 & 0.056 & 0.351 & 16.279 & 1.2 & 3.11 \\
\hline I-III $\boldsymbol{R}$ & 39 & 2.05 & 0.044 & 0.274 & 13.357 & 1.52 & 2.66 \\
\hline III-IV $\boldsymbol{L}$ & 39 & 2.06 & 0.054 & 0.34 & 16.542 & 1.44 & 2.86 \\
\hline III-V $\boldsymbol{R}$ & 39 & 2.01 & 0.061 & 0.381 & 18.927 & 1.09 & 3.06 \\
\hline I-V $\boldsymbol{L}$ & 39 & 4.21 & 0.056 & 0.351 & 8.342 & 3.6 & 5.22 \\
\hline I-V $\boldsymbol{R}$ & 39 & 4.06 & 0.062 & 0.39 & 9.601 & 2.92 & 5.04 \\
\hline
\end{tabular}

Legend: $L=L$ eft, $R=$ right

BAEP results for all the control group seen in Table 2. The left wave V latency in control group and in patients group had a significant mean difference $(0.19) \mathrm{p}<0.05$ and CI $95 \%$. We have also found significant differences in values of I-III left interval $(\mathrm{p}<0.05$, CI $95 \%)$. For the I-V interval 
TABLE 2. BAEP results for the control group

\begin{tabular}{|l|c|c|c|c|c|c|c|}
\hline $\begin{array}{l}\text { WAVE/ } \\
\text { INTERVAL }\end{array}$ & $\mathbf{n}$ & $\bar{X}$ & $\pm \mathbf{s}$ & $\mathbf{s}$ & V\% & Min & Max \\
\hline I $\boldsymbol{L}$ & 50 & 1.7 & 0.046 & 0.328 & 19.273 & 1.08 & 2.4 \\
\hline I $\boldsymbol{R}$ & 50 & 1.69 & 0.048 & 0.337 & 19.965 & 1.2 & 2.58 \\
\hline II $\boldsymbol{L}$ & 50 & 2.7 & 0.039 & 0.278 & 10.322 & 2.17 & 3.26 \\
\hline II $\boldsymbol{R}$ & 50 & 2.73 & 0.053 & 0.373 & 13.673 & 1.95 & 3.63 \\
\hline III $\boldsymbol{L}$ & 50 & 3.76 & 0.034 & 0.243 & 6.453 & 3.19 & 4.37 \\
\hline III $\boldsymbol{R}$ & 50 & 3.71 & 0.039 & 0.274 & 7.387 & 3.06 & 4.43 \\
\hline IV $\boldsymbol{L}$ & 50 & 4.81 & 0.045 & 0.321 & 6.673 & 3.87 & 5.59 \\
\hline IV $\boldsymbol{R}$ & 50 & 4.82 & 0.053 & 0.371 & 7.706 & 4.03 & 5.69 \\
\hline V $\boldsymbol{L}$ & 50 & 5.64 & 0.03 & 0.215 & 3.824 & 5.2 & 6.37 \\
\hline V $\boldsymbol{R}$ & 50 & 5.66 & 0.046 & 0.324 & 5.716 & 4.94 & 6.71 \\
\hline I-III $\boldsymbol{L}$ & 50 & 2.06 & 0.045 & 0.315 & 15.266 & 1.41 & 2.66 \\
\hline I-III $\boldsymbol{R}$ & 50 & 2.01 & 0.04 & 0.284 & 14.108 & 1.42 & 2.52 \\
\hline III-IV $\boldsymbol{L}$ & 50 & 1.88 & 0.032 & 0.227 & 12.089 & 1.56 & 2.63 \\
\hline III-V $\boldsymbol{R}$ & 50 & 1.97 & 0.028 & 0.201 & 10.22 & 1.67 & 2.67 \\
\hline I-V $\boldsymbol{L}$ & 48 & 3.93 & 0.058 & 0.402 & 10.242 & 3.35 & 5.29 \\
\hline I-V $\boldsymbol{R}$ & 50 & 3.99 & 0.058 & 0.411 & 10.292 & 3.09 & 5.19 \\
\hline
\end{tabular}

Legend: $L=$ Left, $R=$ right

there was a mean difference of 0.29 which was very significant for $\mathrm{p}<0.001$ and $\mathrm{F}>\mathrm{F} 0.001$, CI 95\%. The left wave I latency was in a significantly correlation ( $\mathrm{p}<0.005, \mathrm{CI}=95 \%)$ with the duration of the disease, $\mathrm{R}=0.286$ (28\%), CRP $\mathrm{p}<0.05, \mathrm{Cl} 95 \%$, $\mathrm{R}=0.458(45 \%)$ and BASDAI, $\mathrm{p}<0.05, \mathrm{Cl} 95 \%$ and $\mathrm{R}=0.525(52 \%)$. ANOVA test showed the wave I latency was in a significantly correlation with BASFI ( $p<0.05$, C.I. $95 \%)$. A positive and intermediate correlation between both left and right wave I latencies and the type of disease (axial or peripheral), $r=0.385(38 \%)$ and $0.347(34 \%)$ was significant, $\mathrm{p}<0.05$. Pearson correlation between variables wave I latency and Ott index highlights that there is a negative and significant correlation $(\mathrm{p}<0.05)$ where $\mathrm{r}=-0.278(27 \%)$. The disease duration wave one has $r=0.238 \mathrm{stg}(23 \%)$ but insignificant which means that this variable can influence wave 1 but in combination with other factors. There was also a correlation between CRP and right wave I latency. Since regression line is oriented from the bottom up, with the points focused on the right, we can conclude that between the right wave I and CRP there is a close and positive correlation as seen in Fig. 1.

Right wave I latency is positively and intermediate correlated with CRP, $r=0.302(30 \%)$, significant for $\mathrm{p}<0.05$. Also age is positively correlated, intermediate to intense and very significantly, with disease duration, $r=0.587$ (58\%). Age was also

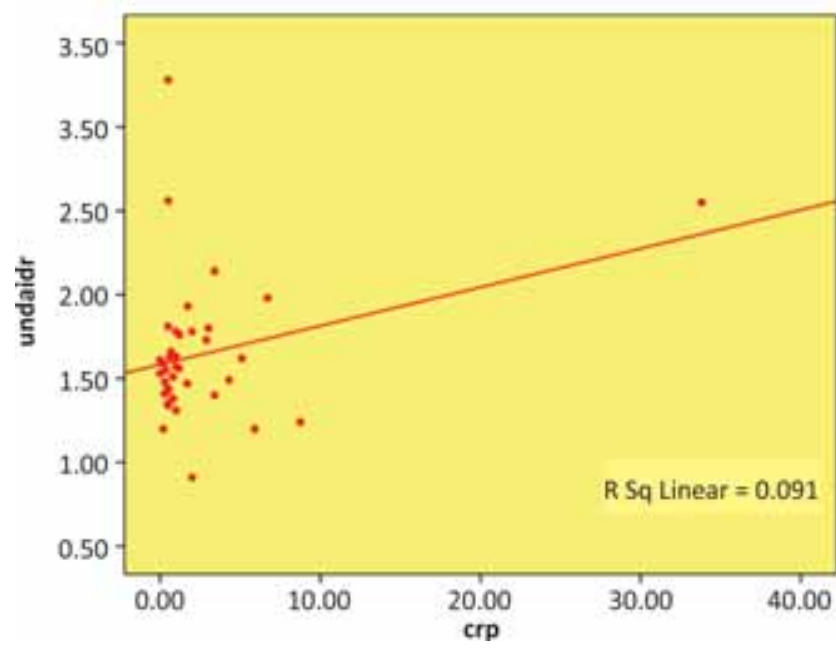

FIGURE 1. Right wave I latency and CRP regression

correlated with Schober index, $\mathrm{r}=-0.536(53 \%)$, and chest expansion measurement, $r=-0.622(62 \%)$. Left wave II latency is significant correlated with disease duration, Ott index, ESR, BASDAI and chest expansion measurement, $\mathrm{p}<0.05$ and $\mathrm{CI}$ $95 \%$. Left wave IV latency is negatively significant correlated with Schober test and Ott index. Both left and wright IV waves are positively correlated with type of disease. Right wave V latency is correlated with CRP and type of disease.

There were differences of the latencies in the group of SA patients treated with TNF alpha blockers compared with the group with AINS/DMARDs. Results of BAEP in group treated with TNF alpha blockers and the group with other pharmacological treatment may be seen in Table 3 and Table 4.

TABLE 3. BAEP results in patients with TNF alpha blockers

\begin{tabular}{|l|c|c|c|c|c|c|c|}
\hline $\begin{array}{l}\text { WAVE/ } \\
\text { INTERVAL }\end{array}$ & $\mathbf{n}$ & $\bar{X}$ & $\mathbf{\pm} \mathbf{s}^{\bar{x}}$ & $\mathbf{s}$ & V\% & Min & Max \\
\hline & 14 & 1.62 & 0.082 & 0.306 & 18.826 & 1.12 & 2.51 \\
\hline & 14 & 1.64 & 0.08 & 0.299 & 18.26 & 1.31 & 2.56 \\
\hline & 14 & 2.78 & 0.133 & 0.497 & 17.866 & 2.18 & 4.04 \\
\hline & 14 & 2.66 & 0.078 & 0.293 & 11.039 & 2.21 & 3.49 \\
\hline & 14 & 3.88 & 0.121 & 0.452 & 11.676 & 3.31 & 4.9 \\
\hline & 14 & 3.71 & 0.083 & 0.31 & 8.345 & 3.2 & 4.39 \\
\hline & 14 & 4.96 & 0.096 & 0.359 & 7.236 & 4.38 & 5.57 \\
\hline & 14 & 4.71 & 0.083 & 0.31 & 6.59 & 4.14 & 5.09 \\
\hline & 14 & 5.89 & 0.096 & 0.359 & 6.104 & 5.19 & 6.51 \\
\hline & 14 & 5.68 & 0.073 & 0.275 & 4.83 & 5.18 & 6.17 \\
\hline & 14 & 2.08 & 0.06 & 0.223 & 10.755 & 1.57 & 2.37 \\
\hline & 14 & 2.08 & 0.06 & 0.223 & 10.755 & 1.57 & 2.37 \\
\hline & 14 & 2.04 & 0.087 & 0.326 & 16.007 & 1.44 & 2.61 \\
\hline & 14 & 1.97 & 0.107 & 0.401 & 20.35 & 1.09 & 2.63 \\
\hline & 14 & 4.27 & 0.087 & 0.324 & 7.596 & 3.6 & 4.74 \\
\hline & 14 & 4.05 & 0.109 & 0.407 & 10.064 & 2.92 & 4.44 \\
\hline
\end{tabular}


TABLE 4. BAEP results in patients with AINS/SSZ

\begin{tabular}{|l|c|c|c|c|c|c|c|}
\hline $\begin{array}{l}\text { WAVE/ } \\
\text { INTERVAL }\end{array}$ & $\mathbf{n}$ & $\bar{X}$ & $\mathbf{\pm} \mathbf{s}^{\bar{x}}$ & $\mathbf{s}$ & V\% & Min & Max \\
\hline & 25 & 1.61 & 0.087 & 0.435 & 26.989 & 0.77 & 3.23 \\
\hline & 25 & 1.65 & 0.096 & 0.482 & 29.266 & 0.91 & 3.28 \\
\hline & 25 & 2.69 & 0.129 & 0.644 & 23.973 & 1.67 & 5.31 \\
\hline & 25 & 2.83 & 0.2 & 0.998 & 35.308 & 1.87 & 6.99 \\
\hline & 25 & 3.74 & 0.134 & 0.67 & 17.902 & 2.65 & 6.25 \\
\hline & 25 & 3.68 & 0.113 & 0.563 & 15.319 & 2.72 & 5.43 \\
\hline & 25 & 4.76 & 0.137 & 0.685 & 14.384 & 3.71 & 7.29 \\
\hline & 25 & 4.76 & 0.114 & 0.572 & 12.014 & 3.72 & 6.26 \\
\hline & 25 & 5.8 & 0.136 & 0.681 & 11.747 & 5.17 & 8.45 \\
\hline & 25 & 5.72 & 0.103 & 0.515 & 9.005 & 4.98 & 7.2 \\
\hline & 25 & 2.03 & 0.06 & 0.301 & 14.823 & 1.52 & 2.66 \\
\hline & 25 & 2.03 & 0.06 & 0.301 & 14.823 & 1.52 & 2.66 \\
\hline & 25 & 2.07 & 0.071 & 0.354 & 17.112 & 1.51 & 2.86 \\
\hline & 25 & 2.03 & 0.075 & 0.375 & 18.455 & 1.6 & 3.06 \\
\hline & 25 & 4.18 & 0.074 & 0.369 & 8.822 & 3.69 & 5.22 \\
\hline & 25 & 4.07 & 0.078 & 0.388 & 9.541 & 3.29 & 5.04 \\
\hline & & & & & &
\end{tabular}

\section{CONCLUSIONS}

This study highlights some abnormalities of BAEP in patients with AS. The results have shown differences between the control group and the patients with AS in most of the wave latencies. Correlations Schober test, Ott index, chest expansion measurement and BASDAI were significant for some waves. CRP seems to be more valuable than ESR as a possible marker for neurologic subclinical involvement. Axial AS is more likely to be associated with BAEP abnormalities. There were differences of the latencies in the group of SA patients treated with TNF alpha blockers compared with the group with AINS/DMARDs. Multiple sclerosis or demyelination due to administration of TNF alpha blockers should be excluded in medical practice. Collaboration between neurologists and rheumatologists should be considered in monitoring AS patients.

\section{Acknowledgement}

This work received financial support through the "Program of excellence in multidisciplinary doctoral and postdoctoral research in chronic diseases" contract number POSDRU/159/1.5/S/ 133377, financed by the European Social Fund through "Human Resources Development" Operational Programme 2007-2013.

\section{Disclosure statement}

The authors have declared no conflicts of interest.

\section{REFERENCES}

1. Sieper J., Braun J., Rudwaleit M., Boonen A., Zink A. Ankylosing spondylitis: an overview. Ann Rheum Dis 2002; 61 Suppl 3:iii8-18.

2. Gran J.T., Husby G., The epidemiology of ankylosing spondylitis. Semin Arthritis Rheum 1993; 22:319-34.

3. Khan M.A. Spondyloarthropathies. Rheum Dis Clin North Am 1992; 18(1):1-276

4. C. Olerud, A. Frost, J. Bring, Spinal fractures in patients with ankylosing spondylitis, European Spine Journal, 1996, 5(1), 51-55

5. Ginsburg W.W., Cohen M.D., Miller G.M., et al. Posterior vertebral body erosion by arachnoid diverticula in cauda equina syndrome: an unusual manifestation of ankylosing spondylitis. J Rheumatol. 1997; 24:1417-20

6. Khedr E.M., Rashad S.M., Hamed S.A., et al. Neurological complications of ankylosing spondylitis: neurophysiological assessment. Rheumatol Int. 2009; 29:103

7. Gündüz O.H., Kiralp M.Z., Ozçakar L., et al. Nerve conduction studies in patients with ankylosing spondylitis. J Natl Med Assoc. 2010; 102:243-6.

8. Pillay N., Hunter T. Delayed evoked potentials in patients with ankylosing spondylitis. J Rheumatol. 1986; 13:137-41.

9. Muharrem Cidem, Zerrin Sahin, Teoman Aydin, Fikret Aysal, Somatosensory Evoked Potential Findings in Ankylosing Spondylitis, Eurasian J Med. 2014, 46(1): 42-46.

10. Hanrahan P.S., Russel A.S., McLean D.R. Ankylosing spondylitis and multiple sclerosis: an apparent association? J Rheumatol. 1988; $15: 1542-4$

11. Libbrecht N., De Bleecker J. Ankylosing spondylitis and multiple sclerosis. Acta Clin Belg. 1999; 54:30-2.

12. Calin A. Is there an association between ankylosing spondylitis and multiple sclerosis? Ann Rheum Dis. 1989; 48:971-2.

13. Khan M.A., Kushner I. Ankylosing spondylitis and multiple sclerosis: a possible association. Arthritis Rheum. 1979; 22:784-6.

14. W. Hitman G.J., K. Han M.A. Unusual occurrence of ankylosing spondylitis and multiple sclerosis in a black patient. Cleve. Clin. J. Med., 1989, 56 (8):819-822

15. C. Ellerini M., G Abbrielli S., B Ongi S.M. Cerebral magnetic resonance imaging in a patient with ankylosing spondylitis and multiple sclerosis syndrome. Neuroradiology, $2001 \mathrm{Dec}, 43$ (12): 1067-1069

16. M. Ramos-Casals, Roberto-Perez-Alvarez, C. Diaz-Lagares, M.J. Cuadrado, M.A. Khamashta, "Autoimmune diseases induced by biological agents: a double-edged sword?" Autoimmunity Reviews, 9(3) 188-193, 2010

17. K. Nozaki, R.M. Silver, D.E. Stickler et al., "Neurological deficits during treatment with tumor necrosis factor-alpha antagonists," The American Journal of the Medical Sciences, 342, no. 5, 352-355, 2011.

18. L.J. Mejico, "Infliximab-associated retrobulbar optic neuritis," Archives of Ophthalmology, 122, 5, 793-794, 2004.

19. Mohan N., Edwards E.T., Cupps T.R., Oliverio P.J., Sandberg G., et al. Demyelination occurring during anti-tumor necrosis factor alpha therapy for inflammatory arthritides. Arthritis Rheum. 2001; 44:2862-2869.

20. E. Andreadou, E. Kemanetzoglou, Ch. Brokalaki, M.E. Evangelopoulos, C. Kilidireas, A. Rombos, and E. Stamboulis, Demyelinating Disease following Anti-TNFa Treatment: A Causal or Coincidental 
Association? Report of Four Cases and Review of the Literature, Case Reports in Neurological Medicine, 2013, doi:10.1155/2013/ 671935

21. C. Faillace, J.R. de Almeida, J.F. de Carvalho, "Optic neuritis after infliximab therapy, Rheumatology International, vol. 33, no. 4, pp. 1101-1103, 2013.

22. A. Fromont, J. De Seze, M.C. Fleury, J.F. Maillefert, T. Moreau, Inflammatory demyelinating events following treatment with anti-tumor necrosis factor, Cytokine, 45, 2, 55-57, 2009

23. P. Lozeron, C. Denier, C. Lacroix, D. Adams, "Long-term course of demyelinating neuropathies occurring during tumor necrosis factor-a-blocker therapy," Archives of Neurology, vol. 66, no. 4, pp. 490-497, 2009.
24. S.J. Shin, A.N. Baer, H.J. Kwon, E.J. Papadopoulos, J.N. Siegel, "Guillain-Barré and Miller Fisher syndromes occurring with tumor necrosis factor a antagonist therapy," Arthritis and Rheumatism, vol. 54, no. 5, pp. 1429-1434, 2006

25. Scheinfeld $\mathbf{N}$. A comprehensive review and evaluation of the side effects of the tumor necrosis factor alpha blockers etanercept, infliximab and adalimumab. J Dermatolog Treat. 2004; 15:280-294.

26. Goie The H.S., Steven M.M., van der Linden S.M., Cats A. Evaluation of diagnostic criteria for ankylosing spondylitis: a comparison of the Rome, New York and modified New York criteria in patients with a positive clinical history screening test for ankylosing spondylitis. Br J Rheumatol. 1985 24(3):242-9. 